\title{
ESTADO DA ARTE DA BACIA HIDROGEOLÓGICA DO SISTEMA LACUSTRE BONFIM-RN, NORDESTE DO BRASIL
}

\author{
Roberto Pereira ${ }^{1}$ \\ João Abner Guimarães Junior² \\ Gerson Cardoso da Silva Junior ${ }^{3}$
}

\begin{abstract}
RESUMO
Devido a implantação do sistema adutor Agreste Trairi Potengi, diversos estudos tem sido realizados no sistema lacustre Bonfim - RN, todavia o entendimento do funcionamento hidrogeológico do aqüífero livre tem se mostrado conflitante, baseando-se em modelos de fluxos convergentes ou divergentes em relação à lagoa do Bonfim. Outros, por sua vez, consideraram a existência de um único exutório, o riacho Boacica. Os resultados obtidos neste trabalho mostraram que o sistema de fluxos subterrâneos é bastante complexo, o que deve ter levado a diversas interpretações.
\end{abstract}

Palavras-chave: Lagoa do Bonfim, aqüífero livre, bacia hidrogeológica

\begin{abstract}
After the construction of the Agreste- Trairi-Potengi aqueduct, located in Rio Grande do Norte State, several studies have been carried out on Bonfim lake hydrologic system, source of water for the aqueduct. Nevertheless, the hydrologic behavior of the water table aquifer has been the subject of various and sometimes conflicting interpretations, since some authors consider a convergent groundwater flow, while others admit a divergent model related to lake Bonfim, or even only a single particular discharge point out of the system, the Boacica creek. The results obtained show that the system is very complex, with seasonal changes, which led to a diversity of conclusions.
\end{abstract}

Keywords: Lake Bonfim, Lake-groundwater relationship, groundwater managemnt.

\section{Apresentação e Objetivo}

O sistema lacustre Bonfim é composto principalmente pelas lagoas do Bonfim (a maior de todas e com aproximadamente 9 $\mathrm{Km}^{2}$ de espelho de água), Redonda, Boa Água, Ferreira Grande, Carcará e Urubu e situa-se cerca de $25 \mathrm{Km}$ de Natal (capital do estado), em direção ao litoral sul. Encontrase inserido dentro de um bloco triangular, tendo, ao norte, o rio Pium; ao sul, o rio Trairi e, a leste, a linha de costa do oceano Atlântico (Figura 1), compreendendo uma área de apenas $1,5 \%$ do estado do Rio Grande do Norte, mas que atende, atualmente, às necessidades hídricas de pelo menos $35 \%$ de sua população. O aumento de demanda de água, no litoral Oriental do Rio Grande do Norte, onde os recursos hídricos são de melhor qualidade, deve-se à implantação do sistema adutor Agreste Trairi Potengi (315 km de extensão) para suprir as necessidades das concentrações urbanas do interior do Rio Grande do Norte, todas no semi-árido, beneficiando uma população de 222.336 habitantes, no horizonte do projeto (ano 2016) quando, então, a vazão será de 452 L/S.

\footnotetext{
${ }^{1}$ CEFET-RN, Fone (0xx84) 215.2636, Fax (0xx184) 221.4005, E-mail: bobdudu@digi.com.br, Natal -RN, Brasil.

2 UFRN/LARHISA/CT, Fone (Oxx84) 215.3775, Fax (0xx84) 215.3703, E-mail: abner@ct.ufrn.br, Natal-RN, Brasil.

3 I. GEOCIÊNCIAS-UFRJ, I. do Fundão - Rio de Janeiro, CEP: 21.949-900. Fone/Fax: (0xx21) 590.8091, E-mail: Gerson@acd.ufrj.br, Rio de Janeiro-RJ, Brasil
} 
Este trabalho tem por objetivo caracterizar a bacia hidrogeológica do aqüífero livre do sistema lacustre Bonfim com base na implantação de uma rede de monitoramento estabelecida durante a pesquisa de tese de doutorado do primeiro autor (Pereira 2001). No período de outubro de 1998 a novembro de 2000 foram realizadas medidas de nível d'água mensais, no caso de poços (108 poços), diárias para as lagoas (8 lagoas), além de contar com informações de 5 pluviômetros, sendo três instalados neste trabalho, mas um dos quais pertencentes a uma estação climatológica, situada à margem da lagoa do Bonfim, também construída nesta pesquisa.

\section{Aspectos Gerais do Sistema Lacustre Bonfim}

A região caracteriza-se pela existência de condições quentes e úmidas, com estação seca, no verão (setembro a janeiro), e chuvosa, no outono-inverno (fevereiro a agosto), com média anual em torno de $1273,2 \mathrm{~mm}$. A geologia e geomorfologia da área de estudo retrata a presença de um zoneamento. Nas porções W e SW das lagoas ocorre, compondo os tabuleiros, a Formação Barreiras (Terciário), a qual é caracterizada por sedimentos arenoargilosos com solos latossólicos. Sotoposta a Formação Barreiras ocorre o embasamento hidrogeológico, representado por uma seqüência sedimentar correlacionada ao Cretáceo, sendo constituída por carbonatos e quartzoarenitos bastante cimentados. Na porção central da área onde ocorrem as lagoas, está presente uma cobertura arenosa sobre a Formação Barreiras interpretada como lençóis eólicos. $\mathrm{Na}$ parte leste, margem esquerda do riacho Boacica, encontram-se os campos de dunas parabólicas fixas do Quaternário.

A bacia hidrográfica deste sistema é de difícil caracterização devido à presença de vales fechados nos sedimentos eólicos, divisores topográficos suaves nos tabuleiros e ausência de drenagens, dado a alta capacidade de infiltração dos solos.

\section{Revisão Bibliográfica}

O estudo da disponibilidade hídrica da lagoa do Bonfim realizado pela empresa COSTA (janeiro de 1997) que subsidiou o estudo de impacto ambiental da lagoa do Bonfim para a implantação do sistema adutor supracitado adotou um modelo convergente para a lagoa do Bonfim (Figura 1), outros, no entanto, admitem um comportamento divergente (Figura 2) a partir desta (Pereira et al., 1996; Feitosa e Melo, 1997). Há ainda os que acreditam que o sistema lacustre Bonfim funciona como uma bacia hidrogeológica com apenas um exutório subterrâneo (Figura 3), o riacho Boacica, no setor leste (Lucas Filho et al., 1999).

De um modo geral se pode perceber que os trabalhos anteriores esbarram em sua maioria na falta de dados de uma boa rede de monitoramento hidrodinâmico e hidrometeorológico do sistema lacustre Bonfim, bem como de um período prolongado de observações. Além disso mostraram aspectos conflitantes com relação ao modelo de funcionamento hidrológico do aqüífero livre e a sua interrelação com as lagoas, principalmente com a lagoa do Bonfim, em seu lado leste.

A identificação de uma compartimentação hidrogeológica a $\mathrm{W}$ da lagoa do Bonfim por Melo e Feitosa (1998) veio aumentar a complexidade do entendimento hidrodinâmico deste sistema, sobretudo com relação as suas áreas de recarga e descarga, fugindo do escopo este trabalho. Esta compartimentação ampla atribuída por Melo e Feitosa (op. cit.), por outro lado, é também conflitante com outros trabalhos que consideram a possibilidade de descontinuidades sedimentares através de estruturas tectônicas e afundamentos cársticos (Pereira, 2002). Para se ter uma idéia, Pereira et al. (2000) apontam que a lagoa do Bonfim alimenta o aqüífero inferior, em sua margem SW, conforme correlação entre a variação do seu nível e o nível piezométrico deste aqüífero. 


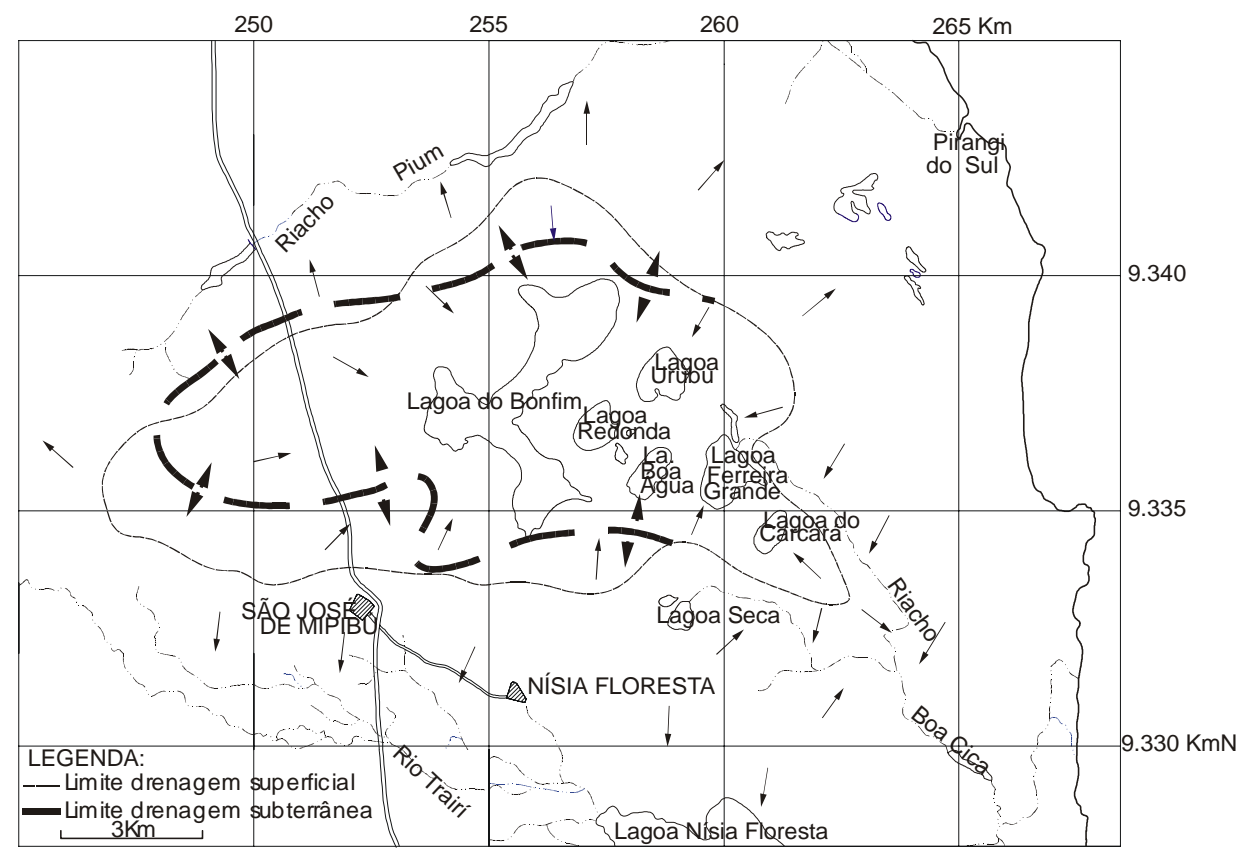

Figura 1 - Área de contribuição das drenagens superficiais e subterrâneas da lagoa do Bonfim (COSTA, 1997). Pode-se perceber que a potenciometria não foi construído no setor SE do sistema lacustre Bonfim.
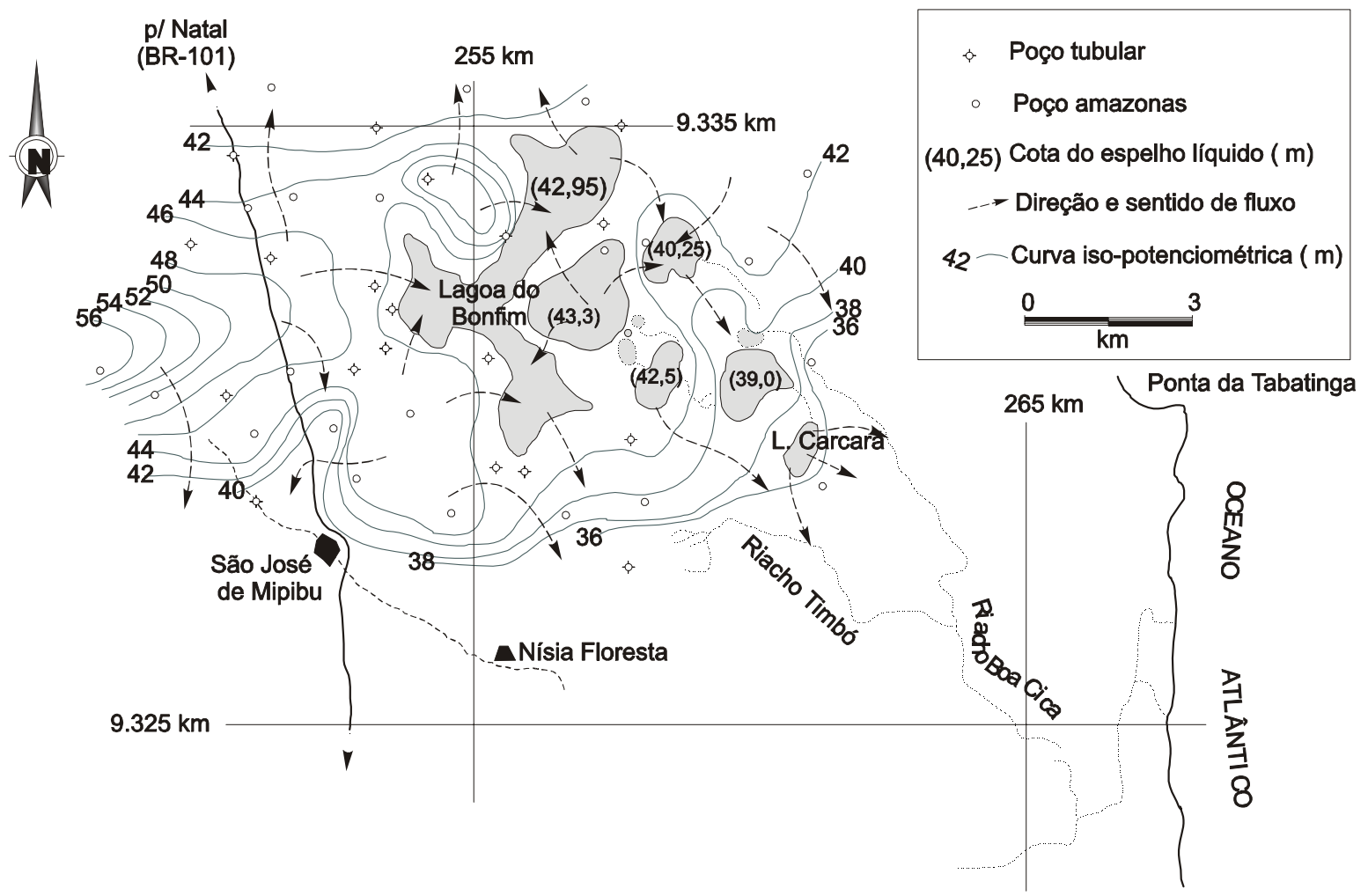

Figura 2 - Potenciometria da área da lagoa do Bonfim (Feitosa \& Melo, 1997). As cotas absolutas foram obtidas do trabalho da COSTA (1997). 


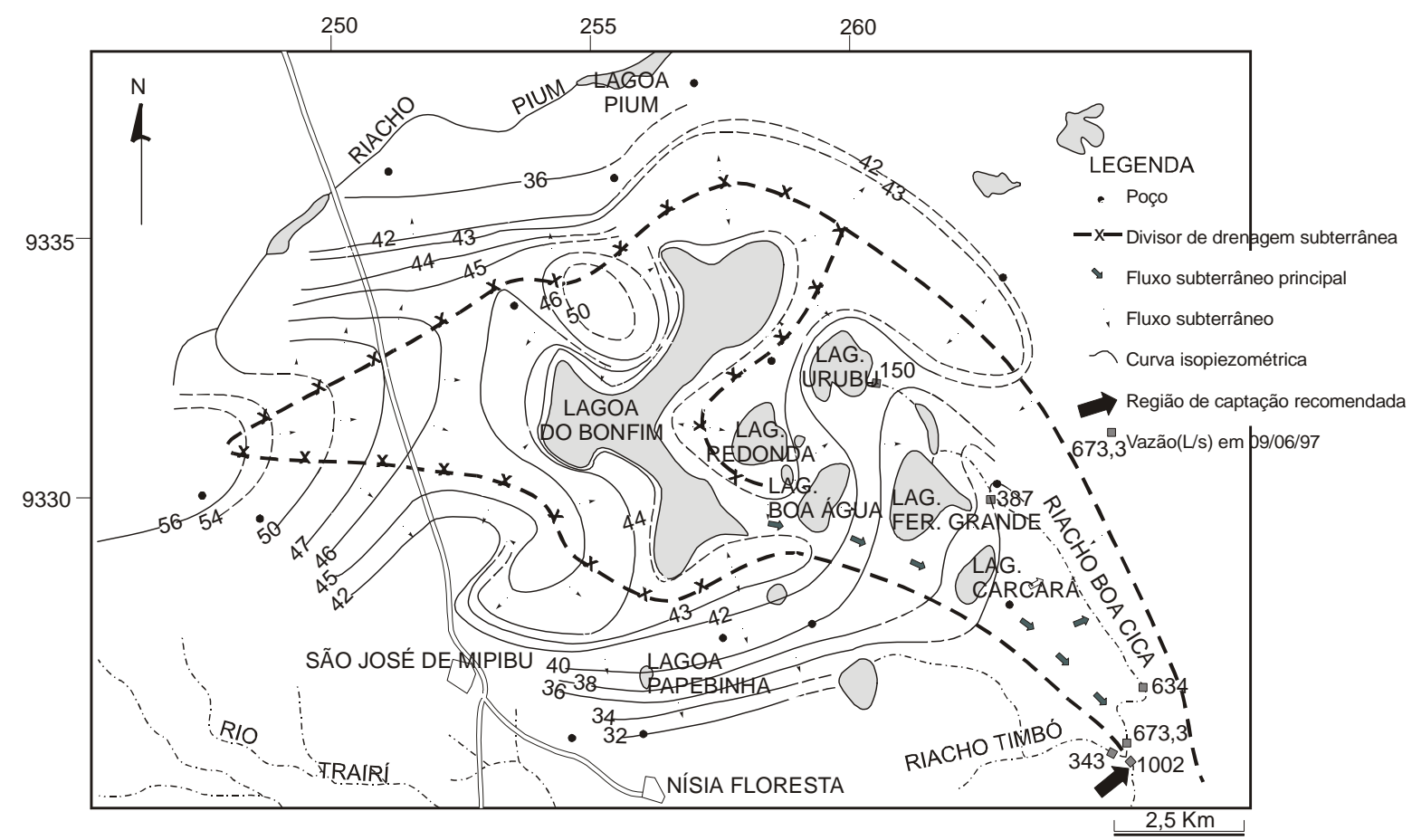

Figura 3 - Drenagem subterrânea do sistema lacustre Bonfim (Lucas Filho et al., 1997). As cotas absolutas foram obtidas do trabalho da COSTA (1997).

\section{Resultados}

O mapa potenciométrico do aqüífero livre da região do Bonfim (Figura 4) foi construído no início de dezembro de 1998, após quatro meses do término do período chuvoso. Pode-se observar que:

- os fluxos subterrâneos que alimentam a lagoa do Bonfim são provenientes de oeste, sendo que 0 alto hidrológico, a oeste, estabelece 0 limite das contribuições subterrâneas desta lagoa. A lagoa do Bonfim, por seu turno, repassa água, subterraneamente, para o rio Pium, em sua extremidade NE, bem como para a lagoa Boa Água, em sua porção SE. No caso específico da lagoa do Pium garante a estabilidade do seu nível até mesmo no período da estiagem (Figura 05). Isto significa dizer que a lagoa do Bonfim tem um papel regulador importante na lagoa do Pium;

- o setor leste desta bacia (campo de dunas) é limitado por um expressivo alto hidrogeológico, o qual apresenta três frentes de escoamentos subterrâneas: uma para o Atlântico, outra para o rio Pium e a última para o riacho Boacica.

O programa de monitoramento intensivo compreendido entre outubro de 1998 e dezembro de 2000, permitiu verificar 0 comportamento do sistema lacustre sob condições pluviométricas abaixo da média (ano de 1999, com $850 \mathrm{~mm}$ ) e acima da média (ano de 2000, com $2080 \mathrm{~mm}$ ). Verificou-se, no entorno da lagoa do Bonfim, que:

- a partir da primeira campanha de medições, os fluxos subterrâneos do aqüífero livre do domínio oeste da lagoa do Bonfim não apresentaram modificações significativas do seu padrão geral de fluxo natural ao longo do monitoramento. As maiores modificações ficaram mesmo por conta da sua margem leste, norte e sul, onde se verifica somente condição de aqüífero livre;

- antes do período chuvoso de 1999, os fluxos subterrâneos do lado leste tiveram maior influência nesta lagoa como conseqüência do desaparecimento de divisores hidrogeológicos (Figura 6 A). Ao término das chuvas os fluxos subterrâneos se comportaram conforme situação inicial, ou seja, apontando o retorno dos divisores hidrogeológicos na parte leste e na extremidade SE (Figura 4), entretanto a influência do Bonfim para a lagoa Papebinha permaneceu constante. Além disso, se verificou a influência dos fluxos subterrâneos provenientes da lagoa Boa Água; 
- até o início da estação chuvosa de 2000, período de esvaziamento do sistema, os divisores hidrogeológicos anteriormente formados desapareceram novamente, semelhante à figura $6 \mathrm{~A}$;
- por fim, logo após o término da estação chuvosa de 2000, os fluxos subterrâneos do aqüífero livre mostraram uma configuração convergente (endorrêica) em relação à lagoa do Bonfim (Figura 6 B).

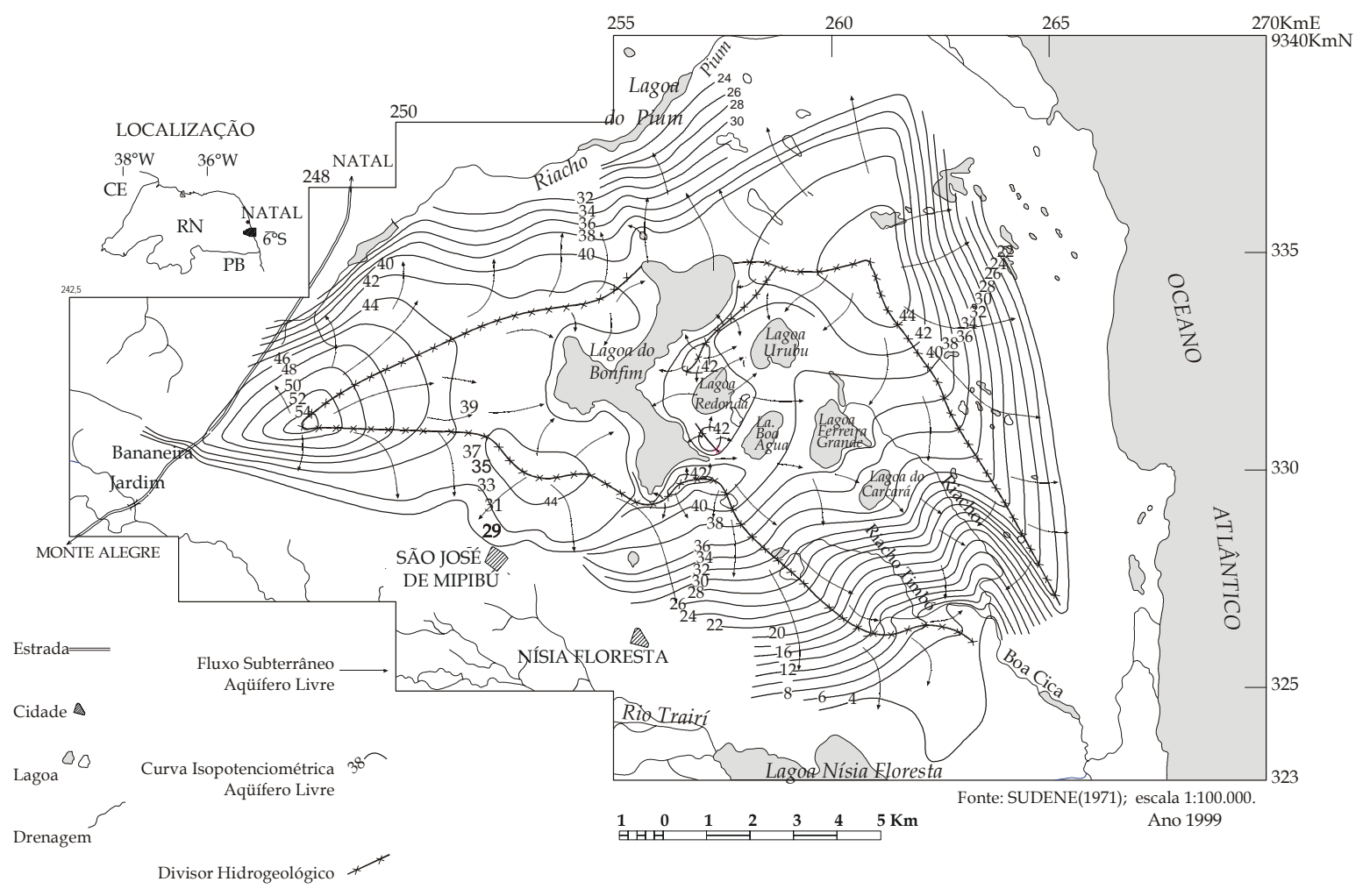

Figura 4 - Bacia hidrogeológica do sistema lacustre Bonfim - RN.

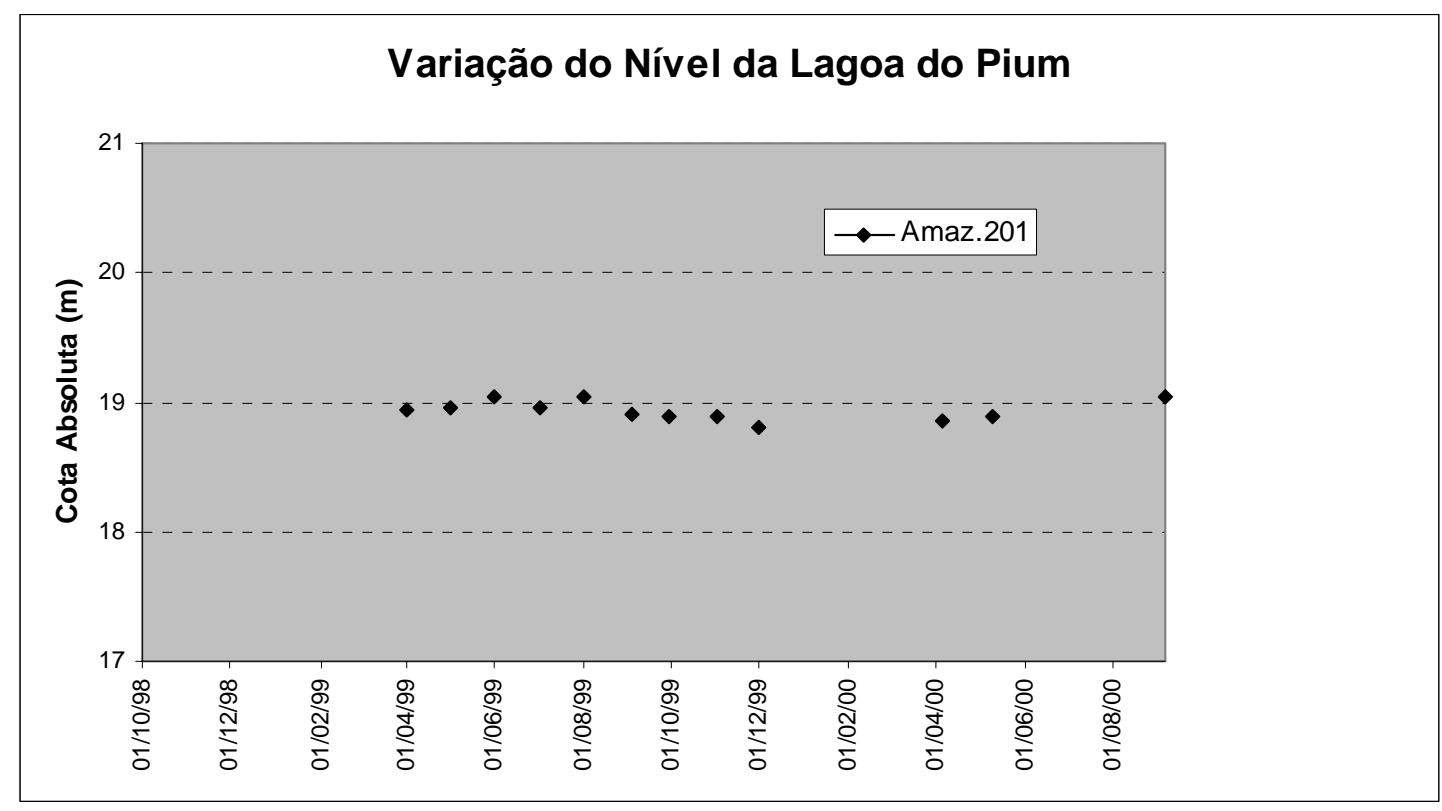

Figura 5 - Comportamento do nível da lagoa do Pium ao longo do tempo. 


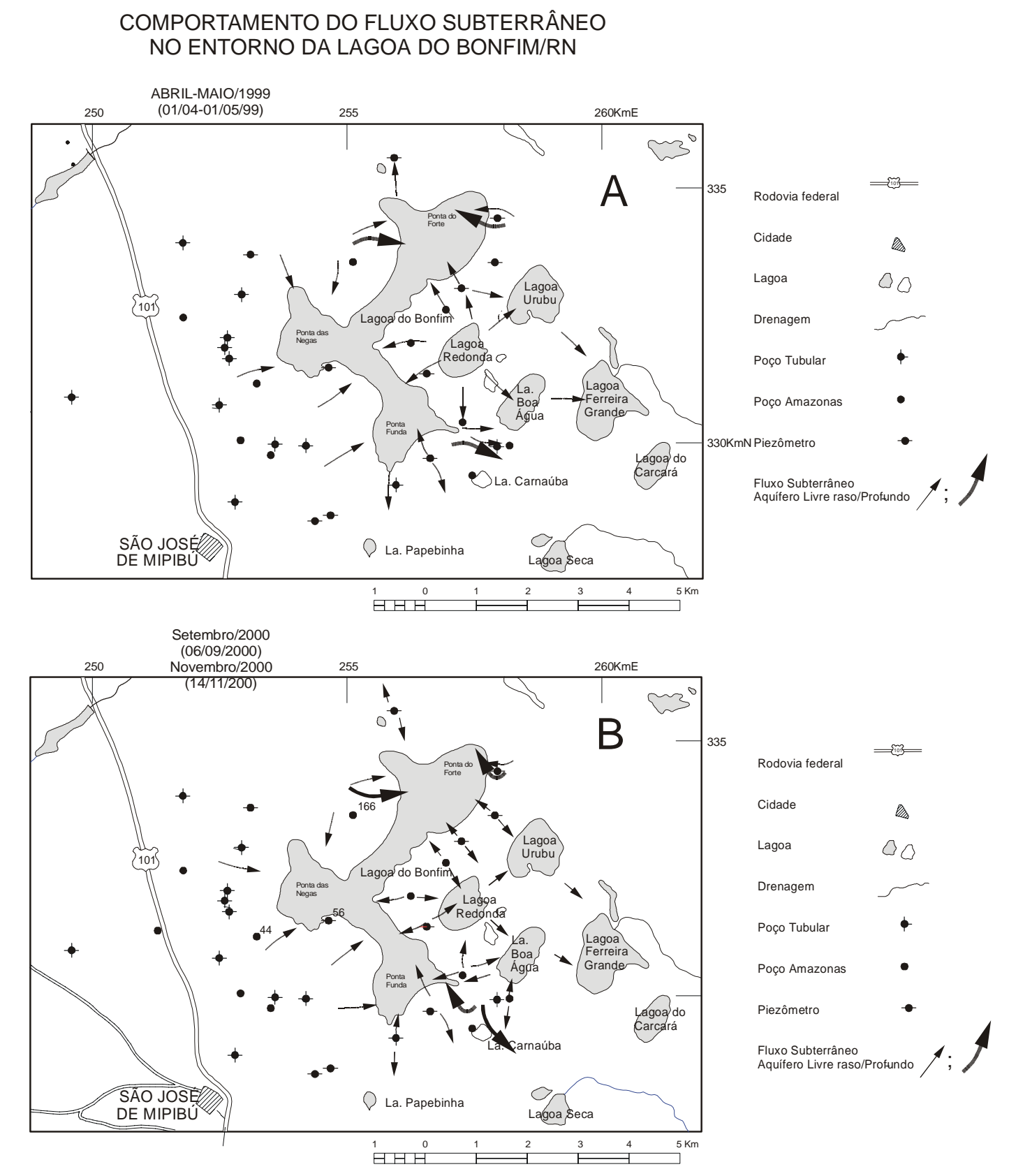

Figura 6 A e B - Fluxos subterrâneos no entorno da lagoa do Bonfim evidenciando inversões de fluxos e comportamento transitório dos divisores hidrogeológicos.

\section{Conclusão}

- Alguns divisores hidrogeológicos são permanentes quando os divisores topográficos são expressivos, outros porém são ignorados pelos fluxos subterrâneos ou podem ser transitórios, a depender da expressão topográfica associada, da pluviometria e das taxas de infiltrações;

- a lagoa do Bonfim é mantida graças a existência dos fluxos subterrâneos provenientes do setor oeste desta lagoa, sua principal área de recarga. Por outro lado, constitui-se, principalmente nos períodos de estiagem, em uma verdadeira caixa de 46 passagem desses mesmos fluxos, em direção ao aqüífero livre, neste caso, no sentido dos rios Pium, Timbó e Trairi, os quais devem ser incluídos em qualquer modelo de simulação desta lagoa;

- a inversão permanente de fluxo da lagoa Boa Água para a lagoa do Bonfim deve-se, provavelmente, ao rebaixamento acentuado provocado pela explotação para o sistema adutor, contribuindo para aumentar a complexidade hidrológica da área;

- os fluxos provenientes da lagoa do Bonfim tem um papel regulador importante na lagoa do Pium, a norte da área, indicado pela 
pequena variação do seu nível, mesmo em épocas de estiagem. O mesmo poderia ser atribuído a vazão específica extremamente elevada do rio Timbó, SE da área, cerca de três vezes a do riacho Boacica e do rio Pium;

- por fim, faz-se necessário que o estudo do sistema lacustre Bonfim passe por uma visão integrada do funcionamento das bacias do riacho Boacica e do Pium.

\section{Agradecimentos}

Os autores agradecem ao Centro Federal de Educação Tecnológica do Rio Grande do Norte (CEFET), a Universidade Federal do Rio Grande do Norte (UFRN) e a Universidade Federal do Rio de Janeiro (UFRJ).

\section{Referências Bibliográficas}

COSTA - Consultoria e Serviços Técnicos e Ambientais Ltda/SERHID (1997). Estudos da Disponibilidade Hídrica da Lagoa do Bonfim. 83 p.

FEITOSA E. C. e MELO J.G. (1997). Relatório Diagnóstico dos dados e Informações disponíveis. Plano Estadual de Recursos Hídricos. Natal, Secretaria Estadual de Recursos Hídricos/Hidroservice engenharia Ltda.

LUCAS FILHO M.; GUIMARÃES JR., J.A.; PEREIRA R. (1999). Perícia Judicial Sobre a Disponibilidade Hídrica da Lagoa do Bonfim para a Implantação do Sistema Adutor Agreste/Trairi/Potengi. In: ABRH, Simp. Brás. Rec. Hidr., 13, Belo Horizonte, CDROW.

MELO J.G. e FEITOSA E.C. (1998). Pesquisa Hidrogeológica do Complexo Lagunar do Bonfim. Convênio UFRN/SEHID, $100 \mathrm{p}$.

PEREIRA R.; CHIAVENATO M.C.; FREITAS J.; REIS L.M.M.; AZEVEDO D.B. (1996). Carta Geotécnica do Município de Nísia Floresta - Rn. Mapa Explicativo. Natal, ETFRN.

PEREIRA R.; SILVA JR G. C.; GUIMARÃES JR J. A. 2000. Analysis of an Alternative Source to Improve the Trairi Water Supply System, RN - Brazil. In: SBG, International geological Congress, 31, Rio de Janeiro Brasil, CD-ROM, Resumo.

PEREIRA, R. (2001). Caracterização Hidrológica do Sistema Lacustre Bonfim $R N$, Brasil. Tese de doutorado, Instituto de Geociências - UFRJ. Rio de Janeiro, Rj, Brasil.

PEREIRA R., SILVA JR G. C.; GUIMARÃES JR J. A. 2000. Considerações a Respeito da Hidrologia e Geologia Estrutural da Região do lagoa do Bonfim - RN. Rev. de Geologia, Vol. 15: 131 - 139. Universidade Federal do Ceará. 